Chronische Herzinsuffizienz - was (noch) nicht in den

\title{
Leitlinien steht
}

Im Beitrag „Chronische Herzinsuffizienz was (noch) nicht in den Leitlinien steht" (Dtsch Med Wochenschr 2015; 140: 406412) muss es auf S. 407, Abschnitt „Angio-
tensin-Rezeptor-Neprylisin-Inhibition“ richtig heißen: „Noch sind aber nicht alle Langzeitnebenwirkungen hinreichend untersucht." 